\title{
Effects of peroxisome proliferator activated receptors- $\alpha$ and $-\gamma$ agonists on estradiol-induced proliferation and hyperplasia formation in the mouse uterus
}

\author{
A G Gunin, A D Bitter, A B Demakov, E N Vasilieva and \\ N V Suslonova \\ Department of Obstetrics and Gynecology, Medical School, Chuvash State University, P.O. Box 86, Cheboksary 428034, Russia \\ (Requests for offprints should be addressed to A G Gunin; Email: drgunin@myrealbox.com)
}

\begin{abstract}
It is suggested that the action of peroxisome proliferatoractivated receptors (PPARs) cross-talks with estrogen signaling in the uterus. However, it is not known how PPAR agonists affect estrogen-dependent processes in the uterus, especially proliferation and morphogenetic changes. The effects of agonists of PPAR $-\alpha$ and $-\gamma$ on proliferative and morphogenetic reactions in the uterus under short- and long-term estrogen treatments were therefore examined. Ovariectomized mice were treated with estradiol dipropionate ( $4 \mu \mathrm{g} / 100 \mathrm{~g}$, s.c., once a week) or vehicle and rosiglitazone (PPAR- $\gamma$ agonist) or fenofibrate (PPAR- $\alpha$ agonist) or with no additional treatment for 2 days or for 30 days. Treatment with estradiol and PPAR agonists for 2 days did not affect uterine mass. In mice treated with estradiol and rosiglitazone for 2 days, proliferation was enhanced and levels of estrogen receptors- $\alpha$ and $\beta$-catenin were decreased in all uterine tissues. Treatment with estradiol and fenofibrate for 2 days had the opposite effects on the parameters tested. In
\end{abstract}

animals treated with estradiol and rosiglitazone for 30 days, uterine mass was increased, abnormal uterine glands and atypical endometrial hyperplasia were found more often and levels of estrogen receptors- $\alpha$ and $\beta$-catenin were decreased. In animals treated with estradiol and fenofibrate for 30 days, uterine mass was decreased, most of the uterine glands had a normal structure, no cases of atypical hyperplasia were diagnosed, proliferative activity was declined and the levels of estrogen receptors- $\alpha$ and $\beta$-catenin were markedly higher. Treatment with rosiglitazone or fenofibrate did not affect the serum estradiol level in the mice which received estradiol together with PPAR agonists for 30 days. Thus, rosiglitazone exerted the proliferative and morphogenetic effects of estradiol, but fenofibrate had the opposite effect. The actions of rosiglitazone and fenofibrate are associated with changes in the expression of estrogen receptors- $\alpha$ and $\beta$-catenin in the uterus.

Journal of Endocrinology (2004) 182, 229-239

\section{Introduction}

Estrogen hormones induce powerful proliferation and changes in the structure of tissues in the uterus (Martin et al. 1973, Bigsby 2002). The culmination of these estrogen-induced changes in proliferation and morphogenesis is the formation of cancer in the endometrium (Emons et al. 2000, Akhmedkhanov et al. 2001). Endometrial cancer can be easily induced in laboratory rodents by treatment with estrogens (Akhmedkhanov et al. 2001). The incidence of this pathology in women is more often when increased estrogen levels or unopposed treatment with estrogen hormones are present (Deligdisch 2000). In addition, it is now absolutely clear that endometrial cancer is an estrogen-dependent disease. In spite of some progress in our understanding of the interactions between estrogen and the uterus and in estrogen hormone signaling, thousands of cases of endometrial cancer are registered each year in all countries. Thus, new aspects of estrogen action in the uterus or new steps in estrogen signaling must be discovered to achieve more effective prevention and treatment of estrogen-dependent diseases.

Peroxisome proliferator-activated receptors (PPARs) and compounds acting on these receptors have a variety of powerful effects in the organism (Elangbam et al. 2001, Shearer \& Hoekstra 2003). There are three types of PPAR, $\alpha, \beta$ and $\gamma$ (Shearer \& Hoekstra 2003). PPAR- $\alpha$ and PPAR- $\gamma$ have been documented in the uterus (Houston et al. 2003). It is also interesting that in the past some shared steps, mostly indirect and controversial, between estrogen signaling and PPAR have been found.

There are some works documenting interactions between PPAR $-\gamma$ and estrogen signaling or uterine physiology. It has been shown that activation of PPAR $-\gamma$ 
Table 1 Experimental design and treatments

\begin{tabular}{|c|c|c|c|c|c|}
\hline & \multicolumn{4}{|c|}{ Treatments and their prolongation (days) } & \multirow[b]{2}{*}{$\begin{array}{l}\text { No. of } \\
\text { animals }\end{array}$} \\
\hline & Estradiol & $\begin{array}{l}\text { Estradiol } \\
\text { vehicle }\end{array}$ & $\begin{array}{l}\text { Rosiglitazone } \\
\text { (PPAR- } \gamma \text { agonist) }\end{array}$ & $\begin{array}{l}\text { Fenofibrate } \\
\text { (PPAR- } \alpha \text { agonist) }\end{array}$ & \\
\hline \multicolumn{6}{|c|}{ Group no. } \\
\hline 1 & 2 & & 2 & & 7 \\
\hline 2 & 2 & & & 2 & 7 \\
\hline 3 & 2 & & & & 7 \\
\hline 4 & & 2 & 2 & & 5 \\
\hline 5 & & 2 & & 2 & 5 \\
\hline 6 & & 2 & & & 5 \\
\hline 7 & 30 & & 30 & & 14 \\
\hline 8 & 30 & & & 30 & 14 \\
\hline 9 & 30 & & & & 14 \\
\hline 10 & & 30 & 30 & & 5 \\
\hline 11 & & 30 & & 30 & 5 \\
\hline 12 & & 30 & & & 5 \\
\hline
\end{tabular}

inhibits the growth of uterine leiomyoma, which is also an estrogen-dependent disease (Houston et al. 2003). It was supposed that this inhibitory action was mediated by the negative influence of PPAR $-\gamma$ on estrogen receptor signaling (Houston et al. 2003). It was found that PPAR- $\gamma$ ligands stimulate secretion of some cytokines (interleukin (IL)-1, IL-6, colony stimulation factor-1 (CSF-1)) by endometrial cells (Wanichkul et al. 2003). There is also an observation showing that PPAR- $\gamma$ ligands reduce chemokine production in human endometrial stromal cells (Pritts et al. 2002). Some reports indicate that PPAR- $\gamma$ could mediate the expression of estrogen target genes and could attenuate estrogen receptors and cyclin $\mathrm{D}_{1}$ levels (Keller et al. 1995, Wang \& Kilgore 2002, Houston et al. 2003, Qin et al. 2003). It has also been shown that PPAR- $\gamma$ coactivator-1 potently enhances the activity of estrogen receptor- $\alpha$ (Kressler et al. 2002). Estradiol treatment was demonstrated to inhibit the ligand-stimulated transactivation of PPAR- $\gamma$ in breast cancer cells (Wang \& Kilgore 2002).

There are also only a few data which show interactions between PPAR- $\alpha$ and estrogen-dependent events in the uterus. PPAR- $\alpha$ agonists have been shown to possess uterotrophic action, which is also synergized with the uterotrophic effect of estradiol (Chandra et al. 1982). However, other researchers have documented no effect (Ashby et al. 1997).

Thus, there is some evidence that PPARs can alter the intracellular estrogen signaling pathway. Hence, it can be suggested that PPARs can affect estrogen-dependent processes, such as proliferation and morphogenetic shifts, in the uterus. However, there are no data on this problem. Therefore, the effects of agonists of PPAR $-\alpha$ and $-\gamma$ on proliferative and morphogenetic reactions in the uterus under short- and long-term estrogen treatment were examined in this work.

\section{Materials and Methods}

\section{Animals}

All procedures were performed in accordance with the UFAW Handbook on the Care and Management of Laboratory Animals and with the Chuvash State University rules for work with laboratory animals. White non-linear female mice $(20 \cdot 33 \pm 0.33$ g; mean \pm S.E.M. $)$ of 3 months of age were used. Animals were obtained from the Animal Department of Chuvash State University (Cheboksary, Russia) and were housed with free access to water and food. Mice were ovariectomized 2 weeks before the experiments were started. All surgical procedures were performed under anesthesia with ketamine and diazepam $\quad(75 \mathrm{mg} / \mathrm{kg}, \quad 0 \cdot 12 \mathrm{mg} / \mathrm{kg}$ respectively, i.p.; Gedeon-Richter, Budapest, Hungary).

\section{Treatment}

Ovariectomized mice were divided into several groups according to treatment, as follows and as shown in Table 1.

The first group of mice $(n=7)$ was treated with a single s.c. injection of estradiol dipropionate in olive oil (Minmedprom, Rostov-Don, Russia) at a dose of $4 \mu \mathrm{g} /$ $100 \mathrm{~g}$ body mass and allowed to drink tap water with 0.005\% (w/v) rosiglitazone (Avandia; GlaxoSmithKline, Brentford, Essex, UK) for 2 days. The second group of mice $(n=7)$ was treated with a single injection of estradiol and fed mouse chow with 0.2\% (w/w) fenofibrate (Sigma Chemical Co., St Louis, MO, USA) for 2 days. The third group of animals $(n=7)$ was treated with a single injection of estradiol with no additional treatment for 2 days. The fourth $(n=5)$, fifth $(n=5)$ and sixth $(n=5)$ groups received a single injection of estradiol vehicle and rosiglitazone or fenofibrate, or with no additional treatment respectively 
for 2 days. The seventh group of mice $(n=14)$ was treated with injections of estradiol once a week and drank water with $0 \cdot 005 \%$ rosiglitazone for 30 days. The eighth group $(n=14)$ received injections of estradiol once a week and was fed mouse chow with $0 \cdot 2 \%$ fenofibrate for 30 days. The ninth group of mice $(n=14)$ was treated with estradiol once a week with no additional treatment for 30 days. The tenth $(n=5)$, eleventh $(n=5)$ and twelfth groups $(n=5)$ received injections of the estradiol vehicle and rosiglitazone or fenofibrate, or with no additional treatments respectively for 30 days.

The uteri were removed $48 \mathrm{~h}$ after the last estradiol or vehicle injection. All animals were injected i.p. with bromodeoxyuridine (BrdU; $5 \mathrm{mg} / 100 \mathrm{~g}$ body mass; Sigma) dissolved in saline $2 \mathrm{~h}$ before the tissues were removed. Organs were removed under deep ether anesthesia. Uteri were weighed and the middle segments of the uterine horns were then placed in modified Bouin's fixative (Gunin et al. 2000) for $6 \mathrm{~h}$ at room temperature, and then dehydrated and embedded in paraffin. Uteri were oriented transversely and cut at 5-7 $\mu \mathrm{m}$.

\section{Estradiol concentration in serum}

In groups 7-12, immediately after the uteri were removed, trunk blood was collected, allowed to clot and then centrifuged at $3000 \boldsymbol{g}$ for $10 \mathrm{~min}$. Serum samples were taken and placed in a refrigerator at $-20{ }^{\circ} \mathrm{C}$ until the analysis was started. Estradiol concentration in serum was determined by the use of the DSL Estradiol EIA Kit (Diagnostic Systems Laboratories Inc., Webster, TX, USA) according to the manufacturer's protocol. A BioRad reader (Hercules, CA, USA) was used. The minimal estradiol concentration which can be detected with these reagents is $7 \mathrm{pg} / \mathrm{ml}$.

\section{Uterine histology}

Histological changes in the uterus were analyzed and diagnosed according to Scully et al. (1994). To estimate the extent of any hyperplastic or neoplastic changes in the endometrium, uterine glands were subdivided into four morphological types: (1) normal glands, (2) cystic glands, (3) glands with daughter glands and (4) a conglomerate of glands, as described (Gunin et al. 2001). The number of each type of glands was calculated in randomly selected sections. No less than three sections from each animal were examined. Results are expressed as the percent of each type of gland. The epithelium of all glands in randomly selected sections was examined and typed as simple, pseudostratified or stratified (multilayered) epithelium. The percent of glands with each type of epithelium was calculated.

\section{The number of mitotic and BrdU-labeled cells}

Proliferative processes were assessed from the number of mitotic and BrdU-labeled cells. Mitoses were counted in sections stained with iron hematoxylin. BrdU was detected immunohistochemically. Sections were hydrated and put in $4 \mathrm{M} \mathrm{HCl}$ for $20 \mathrm{~min}$. Slides were then placed in $0.05 \%(\mathrm{w} / \mathrm{v})$ trypsin in Tris-buffered saline (TBS), $\mathrm{pH}$ $7 \cdot 2-7 \cdot 6$ for $20 \mathrm{~min}$. The sections were rinsed $(3 \times 10 \mathrm{~min})$ in TBS. Non-specific binding was blocked with the avidin and biotin blocking solutions (Vector Laboratories, Burlingame, CA, USA) for $30 \mathrm{~min}$ each. Tissues were then incubated overnight with anti-BrdU mouse monoclonal antibody conjugated with biotin (Caltag Laboratories, Burlingame, CA, USA) diluted 1:50 in TBS with $1 \%$ (v/v) blocking solution (Immunotech, Marseille, France) and $0 \cdot 1 \%(\mathrm{v} / \mathrm{v})$ Triton $\mathrm{X}-100$. After being rinsed in TBS $(3 \times 20 \mathrm{~min})$, sections were incubated for $1 \mathrm{~h}$ with streptavidin conjugated with alkaline phosphatase (Caltag Laboratories) diluted 1:50 in TBS with 0.1\% (v/v) Triton $\mathrm{X}-100$. The sections were then rinsed in TBS $(3 \times 20 \mathrm{~min})$. Alkaline phosphatase activity was revealed through the use of naphthol AS-BI-phosphate (Sigma) and new fuchsin (Sigma) as chromogens. Control sections were stained in a similar manner, except that the primary antibody was replaced with normal mouse serum. The numbers of mitotic and BrdU-labeled cells in luminal epithelium, glandular epithelium, stromal cells and myometrial cells were found as described by Gunin et al. (2001). No less than 3000 epithelial and 10000 stromal or myometrial cells were assessed per mouse. All results are expressed as the percent of mitotic or labeled cells.

\section{Estrogen receptors- $\alpha$ and $\beta$-catenin}

Estrogen receptors- $\alpha$ and $\beta$-catenin were detected using routine indirect immunohistochemical staining. Rabbit anti-estrogen receptor- $\alpha$ polyclonal antibody (Santa Cruz Biotechnology Inc., Santa Cruz, CA, USA) diluted 1:50 and rabbit anti- $\beta$-catenin antiserum (Sigma Chemical Co.) diluted 1:50 were used as primary antibody. For the detection of estrogen receptors, goat anti-rabbit immunoglobulin $G$ antibody conjugated with alkaline phosphatase (Jackson ImmunoResearch Laboratories Inc., West Grove, PA, USA) was used as secondary antibody, and alkaline phosphatase activity was then revealed using naphthol AS-BI-phosphate and new fuchsin as chromogens. For $\beta$-catenin, goat anti-rabbit immunoglobulin $G$ antibody conjugated with peroxidase (Jackson ImmunoResearch Laboratories Inc.) was utilized as secondary antibody, peroxidase activity was then developed by the use of the hydrogen peroxide and diaminobenzidine (Sigma Chemical Co.) technique and slides were also preincubated in $0.1 \%$ hydrogen peroxide in distilled water for $10 \mathrm{~min}$ to block endogenous peroxidase activity. Control sections were stained in a similar manner, except that the primary antibody was replaced with normal rabbit serum. To avoid possible differences in the intensity of staining, sections from all mice were processed simultaneously for each antigen, so that all sections were 
incubated in exactly the same TBS, the same mixtures of primary and secondary antibodies, the same mixture for development of enzyme activity, for the same times, at the same temperature. Intensity of immunostaining was quantified by photometric measurement of optical density (D) for positive stained components of a tissue (Gunin et al. 2002). Photometry was performed using a light microscope and FMEL-1A microspectrophotometer (LOMO, St Petersburg, Russia) by measuring the intensity of light passing through equivalent areas occupied by positive stained structures $(\mathrm{F})$ and by structures with no staining $\left(\mathrm{F}_{0}\right)$. Optical density (light absorption) was calculated from the formula: $\mathrm{D}=\lg \left(\mathrm{F}_{0} / \mathrm{F}\right)$. Positive staining for estrogen receptors $-\alpha$ was detected in the nuclei of all uterine tissues (luminal epithelium, glandular epithelium, stromal cells, myometrial cells). Therefore, the intensity of light passing through the nuclei (F; positive staining) and through the cytoplasm $\left(\mathrm{F}_{0}\right.$; negative staining) was measured in the case of estrogen receptors- $\alpha$. $\beta$-Catenin was detected in luminal and glandular epithelia. Therefore, the intensity of light passing through the cytoplasm of these epithelial cells (F; positive staining) and through the endometrial stromal cells $\left(\mathrm{F}_{0}\right.$; negative staining) was measured in the case of $\beta$-catenin. The level of expression was considered to be the value of the optical density (Gunin et al. 2002, 2004). At least 100 nuclei were analyzed for each structure in each mouse.

\section{Statistics}

Arithmetic means and standards errors were calculated for each data group. The significance of differences was determined by non-parametric Mann-Whitney $U$ test (uterine mass, estradiol serum level, proliferation, estrogen receptors, $\beta$-catenin) and by use of the chi-square test (gland types, epithelium types, pathology). $P<0.05$ was considered to be significant.

\section{Results \\ Estradiol levels in serum}

Estradiol concentrations in serum were measured in the groups treated for 30 days. As expected, estradiol was not detected in any of the groups of ovariectomized mice which were treated with olive oil instead of estradiol (groups 11-13). In control mice treated with estradiol with no additional treatments for 30 days (group 9), estradiol concentration in serum was $136 \pm 12 \mathrm{pg} / \mathrm{ml}$. In animals receiving estradiol and rosiglitazone for 30 days (group 7), the estradiol concentration was $135 \pm 23 \mathrm{pg} / \mathrm{ml}$, and in mice treated with estradiol and fenofibrate (group 8), the estradiol level was $138 \pm 17 \mathrm{pg} / \mathrm{ml}$. There were no statistically significant differences from the data of control mice treated with estradiol only.

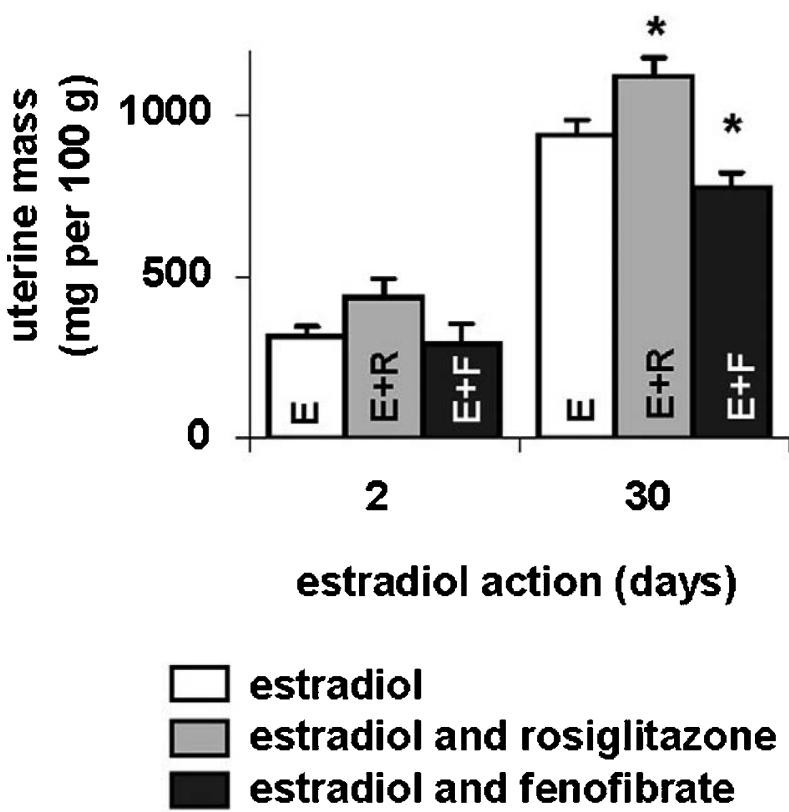

Figure 1 The data on uterine mass (mg/100 g body mass) of ovariectomized mice treated with estradiol alone (open bars, E) or with rosiglitazone (shaded bars, E+R) or fenofibrate (solid bars, $\mathrm{E}+\mathrm{F})$ for 2 or 30 days. Values are means \pm S.E.M. ${ }^{*} P<0 \cdot 05$ (Mann-Whitney $U$ test).

\section{Uterine mass}

The uterine mass of ovariectomized mice receiving olive oil instead of estradiol with no additional treatment for 2 or 30 days (groups 3 and 12) was $123.7 \pm 21.5$ or $120 \cdot 1 \pm 24 \cdot 9 \mathrm{mg} / 100 \mathrm{~g}$ body mass $(n=5)$ respectively. The addition of olive oil treatment to fenofibrate or rosiglitazone for 3 or 30 days had no effect on uterine mass.

In mice receiving estradiol and rosiglitazone for 2 days (group 1), uterine mass was elevated, but this elevation was not significant (Fig. 1). The uterine mass of mice receiving estradiol and fenofibrate for 2 days (group 2) did not differ much from control.

Treatment with estradiol and rosiglitazone for 30 days (group 7) resulted in a $20 \%$ increase in uterine mass, whereas treatment with estradiol and fenofibrate (group 8) produced a $21 \%$ decrease in this parameter (Fig. 1). Changes in 30 -day treatment groups were statistically significant $(P<0 \cdot 05)$.

\section{Uterine histology}

All uteri of ovariectomized mice which were not treated with estradiol and received rosiglitazone or fenofibrate, or with no additional treatment for 2 or 30 days (groups 4-6 and 10-12) were diagnosed as showing atrophic endometrium. All endometrial glands in all these uteri had a narrow lumen and an round, oval or elongated shape (a microscopical reflection of simple tubular glands), 

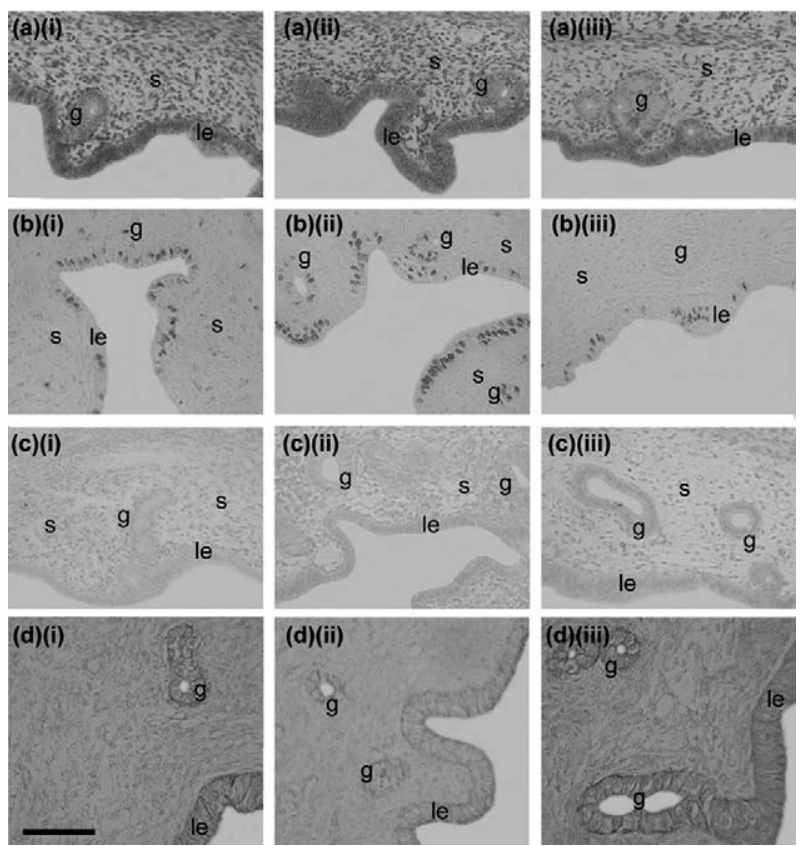

Figure 2 Photomicrographs demonstrating uterine histology (a) and immunohistochemical staining for BrdU (b), estrogen receptors- $\alpha$ (c) and $\beta$-catenin (d) in the uteri of mice treated with estradiol alone (i) or with rosiglitazone (ii) or fenofibrate (iii) for 2 days. No changes in general uterine histology are seen among the groups. There is a marked increase in the number of BrdU-labeled cells (b-ii), a decrease in levels of estrogen receptors- $\alpha$ (c-ii) and $\beta$-catenin (d-ii) in the uterus of mice treated with estradiol and rosiglitazone for 2 days (ii), as compared with controls (b-i, c-i, d-i). On the contrary, 2 days of treatment with estradiol and fenofibrate produces a decrease in the number of BrdU-labeled cells (b-iii), elevated levels of estrogen receptors- $\alpha$ (c-iii) and $\beta$-catenin (d-iii) in the uterus, as compared with controls (b-i, c-i, $\mathrm{d}-\mathrm{i})$. le, luminal epithelium; $\mathrm{g}$, endometrial glands; $\mathrm{s}$, stromal cells. Scale bar $100 \mu \mathrm{m}(\mathrm{a}, \mathrm{b}, \mathrm{c})$ and $200 \mu \mathrm{m}$ (d).

which were regarded as normal. All glands were lined with simple cuboidal epithelium.

In control animals treated with estradiol for 2 days (group 3), there were also only normal endometrial glands lined with cuboidal epithelium (Fig. 2). However, glands were enlarged compared with those in mice which did not receive estradiol. All uteri of mice exposed to estradiol for 2 days were diagnosed as showing early proliferative endometrium. The addition of estradiol treatment with rosiglitazone or fenofibrate for 2 days (groups 1 and 2) did not produce any changes in uterine histology (Fig. 2). All glands were normal, and all uteri were considered as showing early proliferative endometrium.

In control mice receiving estradiol for 30 days (group 9), abnormal glands, especially glands with daughter glands and glands forming conglomerates, were observed (Figs 3 and 4). Glands lined with pseudostratified or atypical stratified epithelium were also found in these uteri (Figs 3 and 4). Atypical endometrial hyperplasia was diagnosed in $42 \%$ of control mice treated with estradiol for 30 days.
In animals treated with estradiol and rosiglitazone for 30 days (group 7), glands with daughter glands, glands forming conglomerates and glands with atypical stratified columnar epithelium were observed more often (Figs 3 and 4). The incidence of atypical endometrial hyperplasia was found in $53 \%$ of cases, and there was no case of normal proliferative endometrium (Figs 3 and 4).

In the uteri of mice treated with estradiol and fenofibrate for 30 days (group 8), most of the glands had a normal shape and there were no gland forming conglomerates. Also, most glands were lined with simple columnar or cuboidal epithelium. In these uteri, no case of atypical endometrial hyperplasia was diagnosed (Figs 3 and 4).

\section{Proliferation}

Proliferation in the uterus was estimated by two criteria, the numbers of mitotic and BrdU-labeled cells.

Treatment with estradiol and rosiglitazone for 2 days (group 1) produced an increase in the numbers of mitotic and BrdU-labeled cells in luminal epithelium, the epithelium of endometrial glands and in stromal and myometrial cells of the uterus (Fig. 5). In mice treated with estradiol and fenofibrate for 2 days (group 2), there was a little decrease in all proliferative parameters in all uterine tissues (Fig. 5).

Treatment with estradiol and rosiglitazone for 30 days (group 7) had no significant effect on both proliferative parameters in all uterine tissues (Fig. 5). Treatment with estradiol and fenofibrate for 30 days (group 8) produced a decrease in the number of mitotic and BrdU-labeled cells in all structures, but this decrease was more expressed, especially in epithelia, than that observed in the 2-day treatment protocol (Fig. 5).

Mice which received the estradiol vehicle (olive oil) and rosiglitazone or fenofibrate or with no additional treatment for 30 days (groups 10-12) had no changes in proliferative parameters in all uterine tissues (Fig. 5). Mitotic and BrdU-labelling indices in all uterine tissues of mice receiving olive oil and rosiglitazone or fenofibrate or with no additional treatment for 2 days (groups 4-6) were not different from those of the 30-day olive oil-treated groups and did not differ among each other.

\section{Estrogen receptors- $\alpha$}

Immunohistochemically, estrogen receptors- $\alpha$ were found in luminal and glandular epithelia, in the stromal and myometrial cells of the uterus. Treatment with estradiol and rosiglitazone either for 2 or 30 days (groups 1 and 7) reduced the level of estrogen receptors- $\alpha$ in all uterine compartments, as compared with that in control animals (groups 3 and 9) treated with estradiol (Figs 2, 3 and 6). However, this decrease was not statistically significant in the 2-day treatment group. 

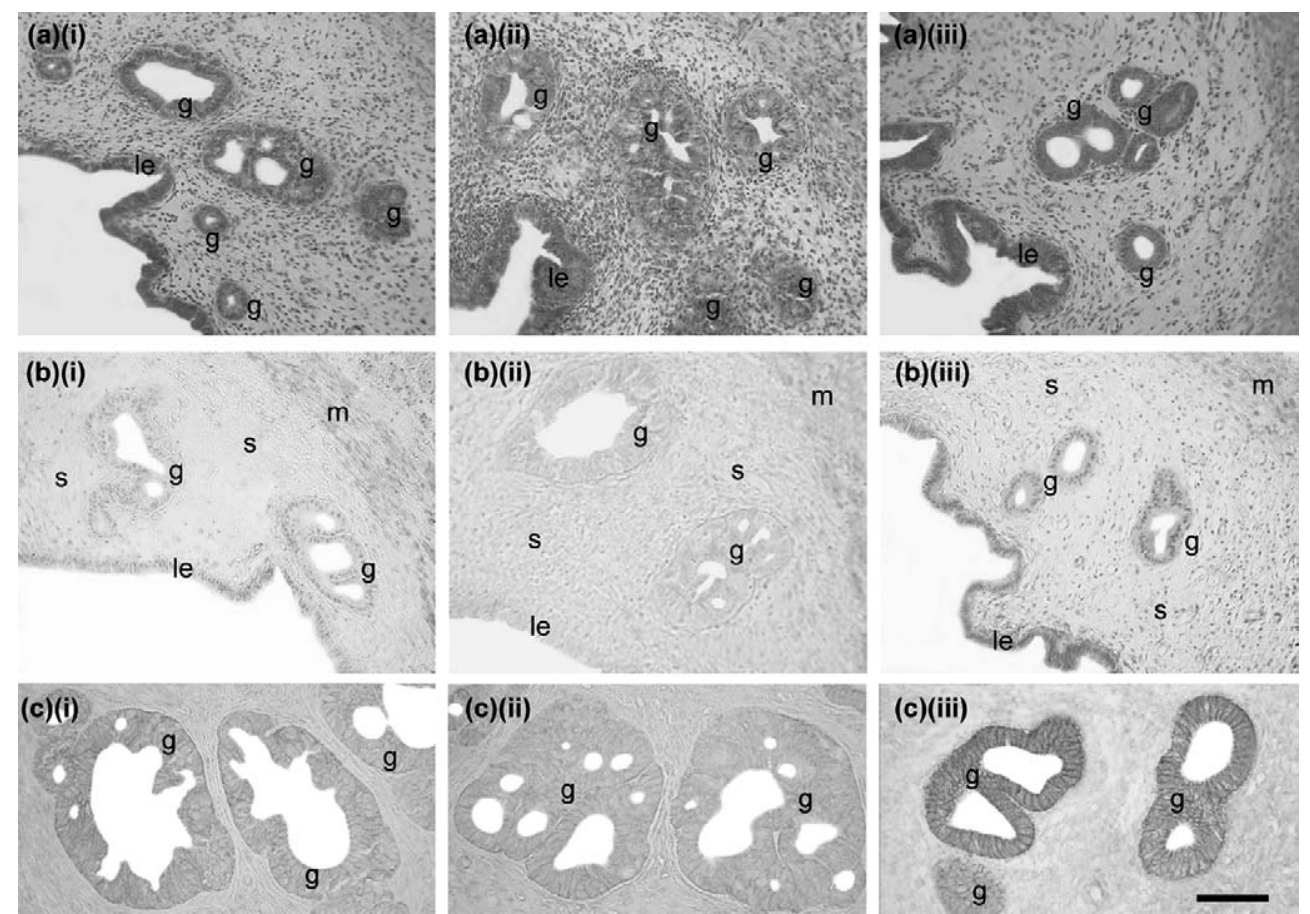

Figure 3 Photomicrographs demonstrating histological findings (a), immunohistochemical staining for estrogen receptors- $\alpha$ (b) and $\beta$-catenin (c) in the uteri of mice treated with estradiol with no additional treatments (i), estradiol and rosiglitazone (ii) and estradiol and fenofibrate (iii) for 30 days. Multiple enlarged glands with a few daughter glands are seen in the uteri of mice receiving estradiol and rosiglitazone (a-ii). In control mice receiving only estradiol (a-i), glands with daughter glands are also present, but in a lower percent of cases. However, normal glands with small dimensions and lined with simple columnar or cuboidal epithelia are also seen in the uteri of control mice (a-i). In mice receiving estradiol and fenofibrate, only normal round glands lined with simple cuboidal or columnar epithelia are present (a-iii). There is a marked decrease in the levels of estrogen receptors- $\alpha$ (b-ii) and $\beta$-catenin (c-ii) in luminal epithelium (le), glandular epithelium (g) and endometrial stromal cells (s) in the uterus of mice treated with estradiol and rosiglitazone for 30 days, as compared with controls (b-i, c-i). An increase in the levels of estrogen receptors- $\alpha$ (b-iii) and $\beta$-catenin (c-iii) is visible in the uterus of mice receiving estradiol and fenofibrate (b-ii, c-ii), as compared with control (b-i, c-i). Scale bar $100 \mu \mathrm{m}(\mathrm{a}, \mathrm{b})$ and $200 \mu \mathrm{m}$ (c).

In groups treated with estradiol and fenofibrate either for 2 or 30 days (groups 2 and 8), the level of estrogen receptors- $\alpha$ in all uterine structures was significantly higher than that in the appropriate controls (groups 3 and 9) (Figs 2, 3 and 6).

Mice which received the estradiol vehicle (olive oil) and rosiglitazone or fenofibrate or with no additional treatment for 30 days (groups 10-12) had no changes in estrogen receptor expression (Fig. 6). The data on expression of estrogen receptors in animals treated with olive oil along with rosiglitazone or fenofibrate or with no additional treatments for 2 days (groups 4-6) were not different from those of the 30-day olive oil-treated groups and did not differ among each other.

\section{$\beta$-Catenin}

$\beta$-Catenin was detected by immunohistochemistry in luminal and glandular epithelia of the uteri of mice in all treatment groups. Treatment with estradiol and rosiglitazone for 2 days (group 1) led to a small decrease in the level of $\beta$-catenin in both epithelia, but the same treatment for 30 days (group 7) led to significant decrease in the level of $\beta$-catenin in both luminal and glandular epithelia (Figs 2, 3 and 7$)$.

In a group treated with estradiol and fenofibrate for 2 days (group 2), the level of $\beta$-catenin was slightly elevated, but the same treatment for 30 days (group 8) produced a significant increase in $\beta$-catenin content in luminal and glandular uterine epithelia (Figs 2, 3 and 7).

The data of mice treated with the estradiol vehicle and rosiglitazone or fenofibrate or with no additional treatment for a month (groups 10-12) are shown in Fig. 7c. There were no differences in $\beta$-catenin level among these groups. The data on $\beta$-catenin level in animals treated with olive oil along with rosiglitazone or fenofibrate or with no additional treatment for 2 days (groups 4-6) were not different from those of the 30-day 


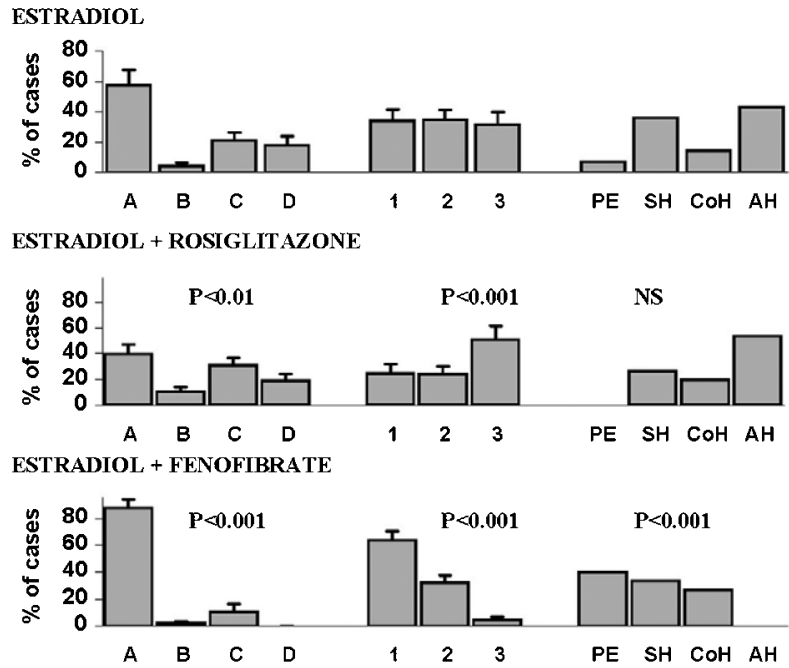

Figure 4 Types of endometrial glands, types of glandular epithelium and pathology diagnosis in uteri of ovariectomized mice treated with estradiol together with rosiglitazone or fenofibrate for 30 days in comparison with those in mice treated with estradiol alone. $\mathrm{PE}$, proliferative endometrium; $\mathrm{SH}$, simple hyperplasia; $\mathrm{CoH}$, complex hyperplasia; $\mathrm{AH}$, atypical hyperplasia; A, normal glands; B, cystic glands; C, glands with daughter glands; D, glands forming conglomerate; 1 , simple columnar epithelium; 2, pseudostratified columnar epithelium; 3, stratified columnar epithelium. Values are means \pm S.E.M. $P$ values (chi-square test). NS, not significant.

olive oil-treated groups and did not differ among each other.

\section{Discussion}

An effect of PPAR agonists is the activation of lipid degradation in peroxisomes. Estrogen hormones have a lipid nature. Therefore, metabolism of these hormones and their concentration in blood can be affected by PPAR agonists. There are controversial data concerning the effects of PPAR agonists on estrogen concentration in blood. One source shows that PPAR ligands, especially PPAR- $\alpha$, decrease estrogen levels in blood (Corton et al. 1997, Xu et al. 2001b). Other data demonstrate activation in estrogen synthesis under PPAR agonists (Liu et al. 1996). There are also studies indicating that the estrogen level remains unaffected with the use of PPAR drugs (Inglis et al. 2001). In our experiments, we used treatment with estradiol together with PPAR- $\alpha$ or PPAR $-\gamma$ ligands. Hence, estradiol levels in blood may be changed by PPAR agonists and our results could be due to this effect. To check this situation, the estradiol concentration in blood was determined in groups with 30-day estradiol treatments. The results clearly showed that the estradiol concentration in mice receiving estradiol with rosiglitazone or fenofibrate did not differ from that of control mice receiving estradiol alone. It can therefore be concluded that our results on the effects of PPAR drugs on estrogeninduced changes in the uterus do not depend on changes in the estradiol level in blood, but are due to other factors which will be analysed below.

In the present research, a group of parameters was used to estimate the action of estradiol in the uterus. Uterine mass is a well-known parameter that depends on estrogen (Emons et al. 2000, Bigsby 2002). Proliferation, which was determined by the numbers of mitotic and BrdU-labeled cells, also depends on estrogen action (Martin et al. 1973, Gunin et al. 2002). In addition, morphogenetic changes, such as shape of glands, type of glandular epithelium and pathology findings, appear in the uterus under long-term estrogen action (Martin et al. 1973, Gunin et al. 2002).

The results mainly showed that rosiglitazone led to an increase in uterine mass, proliferation and in more expressed morphogenetic alterations than in control mice. In the 30-day treated groups, rosiglitazone had almost no effect on proliferation, but this treatment resulted in an increased incidence of atypical hyperplasia. It is known that proliferation and control of cell shape, differentiation, adhesion and apoptosis are regulated by different mechanisms and depend on the work of different genes (Ing \& Ott 1999, Bigsby 2002, Klotz et al. 2002, Simmen et al. 2002). It is possible that rosiglitazone does not affect the genetic machinery which is responsible for proliferation, but affects the pathways regulating the differentiation process that leads to precancerous hyperplasia formation. There are data documenting enhanced tumor formation in the colon under the action of the PPAR- $\gamma$ agonist (Lefebvre et al. 1998, Michalik et al. 2004). Thus, our data demonstrated that rosiglitazone enhances mainly morphogenetic and, to a lesser degree, proliferative estrogen action on the uterus. Other data have indicated that PPAR $-\gamma$ agonists affect one estrogen-inductable gene, but others do not (Keller et al. 1995, Houston et al. 2003).

On the contrary, experiments with fenofibrate have shown that uterine mass, proliferation and morphogenetic shifts were less expressed than in control animals. There was no case of atypical endometrial hyperplasia in the estradiol- and fenofibrate-treated groups. Hence, the effect of fenofibrate can be regarded as anti-estrogenic with regard to the proliferation and morphogenesis.

There has been one paper showing that the PPAR- $\alpha$ agonist clofibrate had no effect on the uterus $(\mathrm{Xu}$ et al. 2001a). Our data have demonstrated the opposite situation. The nature of these contradictions is due to differences in experimental designs and PPAR- $\alpha$ agonists applied in these experiments. In work performed in the laboratory of Dr A H Conney, clofibrate was used as a PPAR- $\alpha$ agonist, estradiol treatment was prolonged for 10 days and only uterine mass was measured with no histological examination (Xu et al. 2001a). We used fenofibrate as the PPAR- $\alpha$ agonist, because it has been shown that this compound is less toxic (Guay 2002). In the present 
(a)

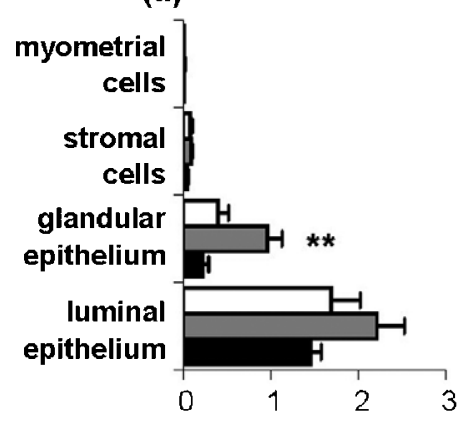

(d)

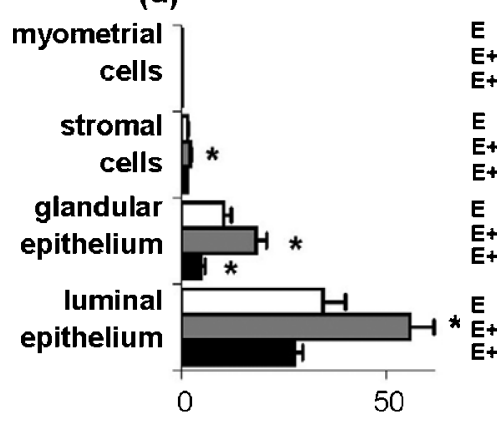

(b)

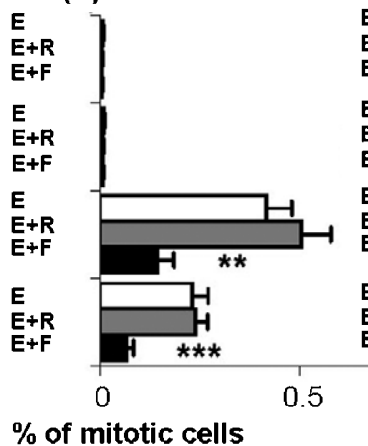

(e)

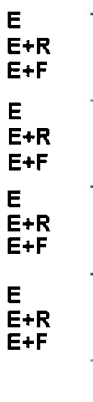

(c)

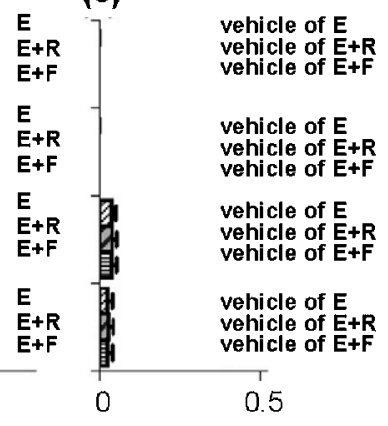

$\%$ of BrdU-labelled cells
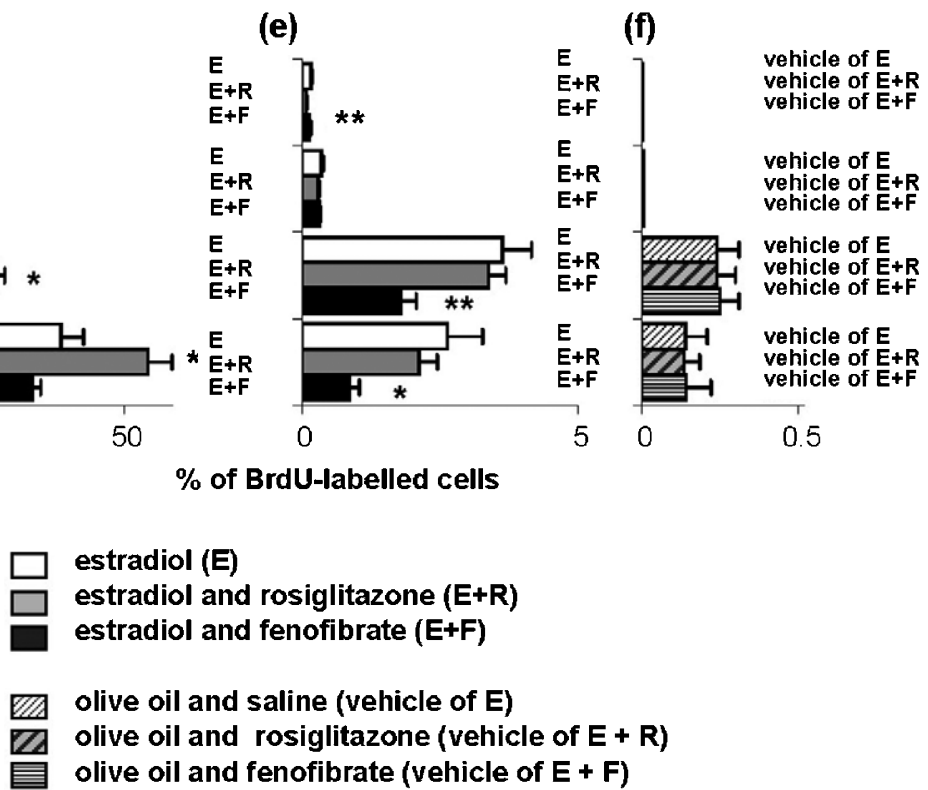

Figure 5 The numbers of mitotic ( $\mathrm{a}$ and $\mathrm{b}$ ), BrdU ( $\mathrm{d}$ and e)-labeled cells in the compartments of the uteri of ovariectomized mice treated with estradiol alone (open bars, E) or with rosiglitazone (shaded bars, E+R) or fenofibrate (solid bars, E+F) for 2 ( $a$ and d) or 30 (b and e) days. The numbers of mitotic (c) and BrdU-labeled cells (f) of mice treated with olive oil (estradiol vehicle) only (finely hatched bars, vehicle of E) or with rosiglitazone (thickly hatched bars, vehicle of E+R) or fenofibrate (parallel line-filled bars, vehicle of $E+F$ ) for 30 days are shown in (c and $f$ ). Values are means \pm S.E.M. ${ }^{*} P<0 \cdot 05,{ }^{* *} P<0 \cdot 01,{ }^{* * *} P<0 \cdot 001$ (Mann-Whitney $U$ test).

research, minimal changes in uterine weight were also registered in the group receiving estradiol and fenofibrate for 2 days, but a marked decrease in uterine mass occurred with prolongation of the treatment to 30 days. Moreover, histological examination clearly showed the effects of fenofibrate on the estrogen-dependent processes in the uterus.

The effects of PPAR agonists on all parameters tested were found only in estrogen-treated mice and not documented in control animals receiving olive oil instead of estradiol. Hence, this situation allows us to suppose that PPAR agonists affect some steps in the mechanism of estrogen action.
To define some possible mechanisms involved in the action of PPAR agonists on estrogen-induced effects, the expression of estrogen receptors- $\alpha$ and $\beta$-catenin in uterine tissues was examined. The results showed that rosiglitazone reduced the level of estrogen receptors- $\alpha$ in all uterine compartments, as compared with the control. In general, the level of receptors in a tissue depends on a balance between their synthesis and degradation (Ing \& Ott 1999, Nephew et al. 2000). Rosiglitazone probably attenuates estrogen receptor synthesis or activates the degradation. Fenofibrate probably has the opposite effect on the processes of receptor synthesis and degradation. Other data have also shown that PPAR $-\gamma$ agonists resulted 


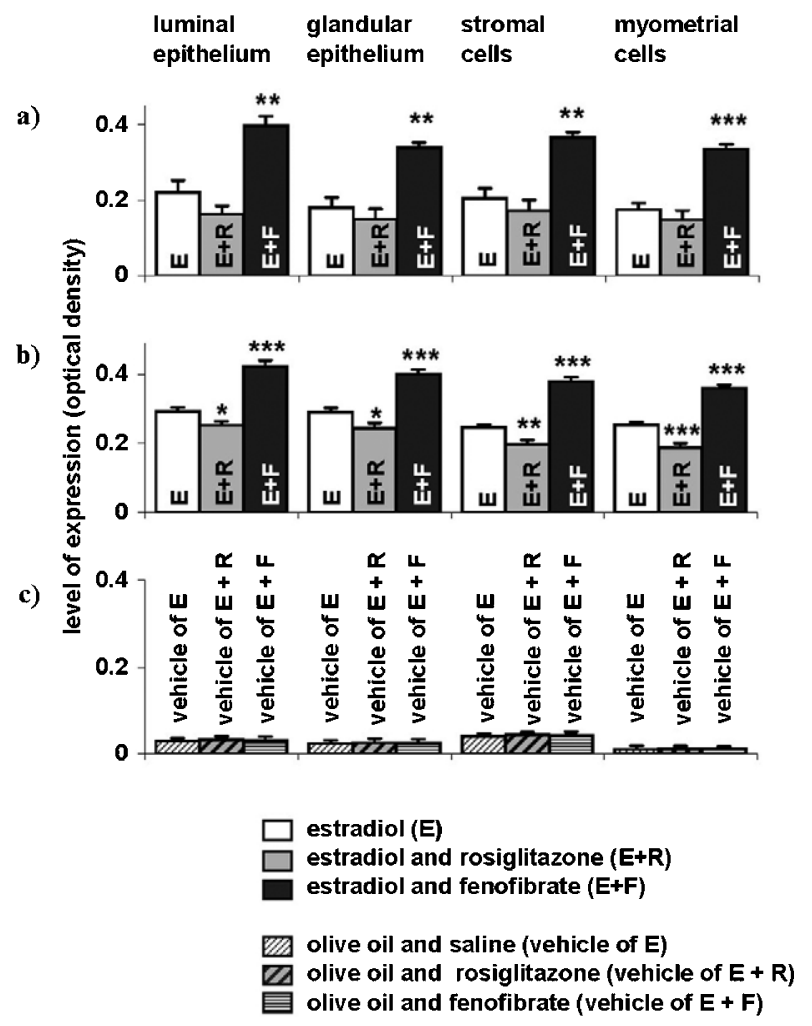

Figure 6 Expression of estrogen receptors- $\alpha$ in uterine tissues of mice treated with estradiol alone (open bars, E) or together with rosiglitazone (shaded bars, E+R) or fenofibrate (solid bars, E+F) for 2 (a) or 30 (b) days. The data from mice treated with olive oil (estradiol vehicle) alone (finely hatched bars, vehicle of E) or with rosiglitazone (thickly hatched bars, vehicle of $E+R$ ) or fenofibrate (parallel line-filled bars, vehicle of $\mathrm{E}+\mathrm{F}$ ) for 30 days are shown in (c). The quantitation of immunostaining was performed by photometric determination of optical density (light absorption) of positively stained components of a tissue. The value of optical density was used as the level of expression. Values are means \pm S.E.M. ${ }^{*} P<0 \cdot 05,{ }^{*} P<0 \cdot 01,{ }^{*}{ }^{*} P<0 \cdot 001$ (Mann-Whitney $U$ test).

in a decrease of estrogen receptors- $\alpha$ in the mammary gland cancer cells MCF-7 that was partially due to proteasome-dependent degradation of the receptors (Houston et al. 2003, Qin et al. 2003). However, there are data which show that PPAR- $\gamma$ agonists can enhance the activity of estrogen receptors- $\alpha$ (Kressler et al. 2002). This latter circumstance may be responsible for an increased incidence of atypical endometrial hyperplasia observed in estrogen- and rosiglitazone-treated animals.

It is interesting to note that in rosiglitazone- and estradiol-treated mice, more intensive estrogen-dependent processes (mass, proliferation, morphogenesis) in the uterus proceed on a lower level of estrogen receptors. In addition, in fenofibrate- and estradiol-treated groups, less intensive estrogen-dependent events are accompanied by increased levels of estrogen receptors. Other data have also shown a)

$\begin{array}{ll}\text { luminal } & \text { glandular } \\ \text { epithelium } & \text { epithelium }\end{array}$
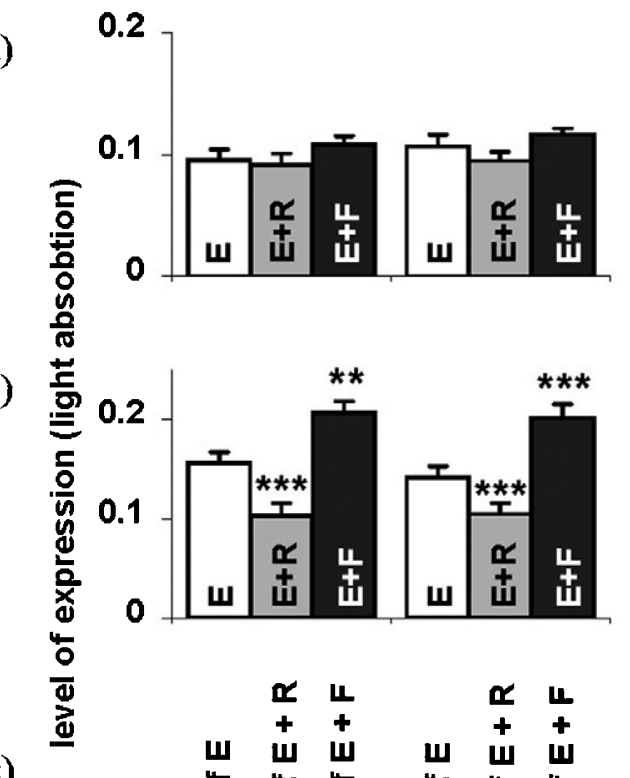

b)

c)
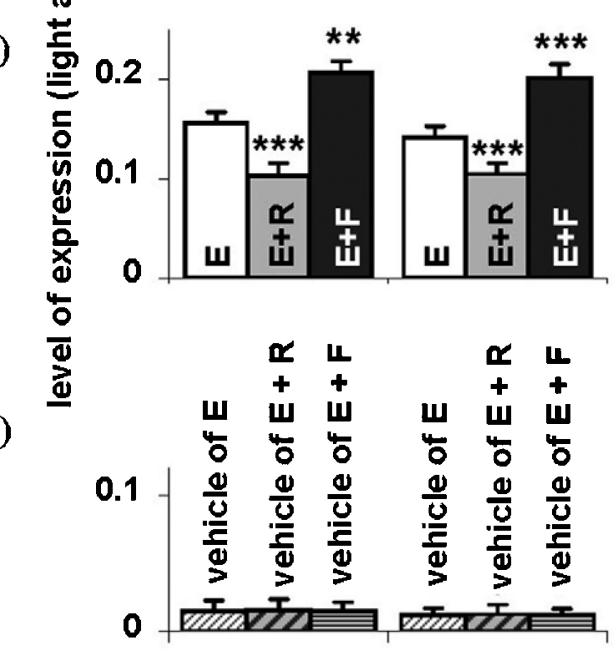

\section{estradiol (E) \\ estradiol and rosiglitazone (E+R) estradiol and fenofibrate (E+F)}

\section{$\mathbb{Z}$ olive oil and saline (vehicle of E) \\ $\square$ olive oil and rosiglitazone (vehicle of $E+R$ ) olive oil and fenofibrate (vehicle of $E+F$ )}

Figure 7 Expression of $\beta$-catenin in uterine epithelia of mice treated with estradiol alone (open bars, E) or together with rosiglitazone (shaded bars, E+R) or fenofibrate (solid bars, E+F) for 2 (a) or 30 (b) days. The data on expression of $\beta$-catenin (c) in uterine epithelia of mice treated with olive oil (estradiol vehicle) only (finely hatched bars, vehicle of E) or with rosiglitazone (thickly hatched bars, vehicle of $E+R$ ) or fenofibrate (parallel line-filled bars, vehicle of $E+F$ ) for 30 days are shown in (c). The quantitation of immunostaining was performed by photometric determination of optical density (light absorption) of positively stained tissues. The value of optical density was used as the level of expression. Values are means \pm S.E.M. ${ }^{* *} P<0 \cdot 01,{ }^{* * *} P<0 \cdot 001$ (Mann-Whitney $U$ test).

that more malignant and less-differentiated endometrial tumors have low levels of estrogen receptors (Sivridis et al. 2001). It is possible that a diminished level of estrogen receptors does not allow estrogens to adequately control the processes of managing morphogenesis that leads to atypical hyperplasia formation. 
$\beta$-Catenin is a component of adhesion junctions and the Wnt pathway (Miller 2002). $\beta$-Catenin synthesis and content in the uterus has been shown to be affected by estrogens and to play a role in endometrial carcinogenesis (Fujimoto et al. 1996, Nei et al. 1999). There is a decrease in $\beta$-catenin expression in uterine epithelia in mice treated with estradiol and rosiglitazone compared with that of mice treated with estradiol alone. However, both shortand long-term treatments with estradiol and fenofibrate showed an increase in $\beta$-catenin content in uterine epithelia. Our results showed that more expressed morphogenetic shifts, which were found in estradioland rosiglitazone-treated mice, are accompanied by a decreased level of $\beta$-catenin. An opposite situation is present in estradiol- and fenofibrate-treated animals. $\beta$-Catenin provides intercellular adhesion. It is possible that if the concentration of $\beta$-catenin is high, cell-cell connection is more stable which protects from the formation of precancerous changes. In the case of low $\beta$-catenin concentration, cell-cell interactions are less solid which provides a situtation for the development of cancer. Other data have also shown a decrease in the level of $\beta$-catenin in the uterus following estrogen action and cancer formation (Fujimoto et al. 1998, Miyamoto et al. 2000, Gunin et al. 2004).

$\beta$-Catenin content in a tissue is also a result of the balance between its synthesis and degradation. It was previously shown that changes in $\beta$-catenin expression can be caused by glycogen-synthase kinase- $3 \beta$, an enzyme which takes part in $\beta$-catenin degradation (Gunin et al. 2003). Other data have shown that estrogen hormones can attenuate $\beta$-catenin biosynthesis in the uterus (Fujimoto et al. 1996). However, further studies are needed to elucidate the roles of PPAR agonists in the regulation of $\beta$-catenin content in the uterus, as well as to define the role of $\beta$-catenin in uterine morphogenesis.

Thus, this research has provided evidence that the PPAR $-\gamma$ agonist rosiglitazone enhances proliferative and morphogenetic estrogen action and supports the development of estrogen-dependent endometrial hyperplasia, and the PPAR- $\alpha$ agonist fenofibrate attenuates the proliferative action of estradiol on the uterus and strongly suppresses the development of precancerous estrogendependent endometrial hyperplasia. We hope that this research will lead to a better understanding of the origin and progression of estrogen-dependent cancers of the female reproductive system.

\section{Acknowledgements}

This work was supported by grants from the Russian Foundation for Basic Research (03-04-48000), from the Ministry of Education of Russia (St Petersburg Competition Center for Fundamental Sciences, E02-6.0-136; Program 'Universities of Russia', yp. 11·01·026). We sincerely thank Professor Ralf Paus (Department of Dermatology, Hamburg University) and Dr Vladimir Botchkarev (Department of Dermatology, Boston University Medical School) for reagents.

\section{References}

Akhmedkhanov A, Zeleniuch-Jacquotte A \& Toniolo P 2001 Role of exogenous and endogenous hormones in endometrial cancer: review of the evidence and research perspectives. Annals of the New York Academy of Sciences 943 296-315.

Ashby J, Lefevre PA, Odum J, Tinwell H, Kennedy SJ, Beresford N \& Sumpter JP 1997 Failure to confirm estrogenic activity for benzoic acid and clofibrate: implications for lists of endocrine-disrupting agents. Regulatory Toxicology and Pharmacology 26 96-101.

Bigsby RM 2002 Control of growth and differentiation of the endometrium: the role of tissue interactions. Annals of the New York Academy of Sciences 955 110-117.

Chandra D, Thulasimany M \& Biswas AR 1982 Uterotropic effect of clofibrate and phenylbutazone in immature female rats. Indian Journal of Physiology and Pharmacology 26 147-151.

Corton JC, Bocos C, Moreno ES, Merritt A, Cattley RC \& Gustafsson JA 1997 Peroxisome proliferators alter the expression of estrogen-metabolizing enzymes. Biochimie 79 151-162.

Deligdisch L 2000 Hormonal pathology of the endometrium. Modern Pathology 13 285-294.

Elangbam CS, Tyler RD \& Lightfoot RM 2001 Peroxisome proliferator-activated receptors in atherosclerosis and inflammation an update. Toxicologic Pathology 29 224-231.

Emons G, Fleckenstein G, Hinney B, Huschmand A \& Heyl W 2000 Hormonal interactions in endometrial cancer. Endocrine-Related Cancer 7 227-242.

Fujimoto J, Ichigo S, Hori M \& Tamaya T 1996 Alteration of E-cadherin, alpha- and beta-catenin mRNA expression in human uterine endometrium during the menstrual cycle. Gynecological Endocrinology 10 187-191.

Fujimoto J, Ichigo S, Hori M \& Tamaya T 1998 Expressions of E-cadherin and alpha- and beta-catenin mRNAs in uterine endometrial cancers. European Journal of Gynaecological Oncology 19 $78-81$.

Guay DR 2002 Update on fenofibrate. Cardiovascular Drug Reviews 20 281-302.

Gunin AG, Sharov AA \& Nikolaev DV 2000 Two month glucocorticoid treatment increases estradiol-induced stromal and myometrial cell proliferation in the uterus of ovariectomized rats. European Journal of Obstetrics, Gynecology and Reproductive Biology $\mathbf{8 8}$ 171-179.

Gunin AG, Mashin IN \& Zakharov DA 2001 Proliferation, mitosis orientation and morphogenetic changes in the uterus of mice following chronic treatment with both estrogen and glucocorticoid hormones. Journal of Endocrinology 169 23-31.

Gunin AG, Emelianov V \& Tolmachev AS 2002 Effect of adrenocorticotrophic hormone on the development of oestrogen-induced changes and hyperplasia formation in the mouse uterus. Reproduction 123 601-611.

Gunin AG, Emelianov VU, Mironkin IU, Morozov MP \& Ivanov VA 2003 Uterine response to estradiol under action of chorionic gonadotropin in mice. International Journal of Gynecological Cancer 13 485-496.

Gunin AG, Emelianov VU, Mironkin IU, Morozov MP \& Tolmachev AS 2004 Lithium treatment enhances estradiol-induced proliferation and hyperplasia formation in the uterus of mice. European Journal of Obstetrics, Gynecology and Reproductive Biology 114 83-91.

Houston KD, Copland JA, Broaddus RR, Gottardis MM, Fischer SM \& Walker CL 2003 Inhibition of proliferation and estrogen receptor 
signaling by peroxisome proliferator-activated receptor gamma ligands in uterine leiomyoma. Cancer Research 63 1221-1227.

Ing NH \& Ott TL 1999 Estradiol up-regulates estrogen receptor-alpha messenger ribonucleic acid in sheep endometrium by increasing its stability. Biology of Reproduction 60 134-139.

Inglis AM, Miller AK, Culkin KT, Finnerty D, Patterson SD, Jorkasky DK \& Freed MI 2001 Lack of effect of rosiglitazone on the pharmacokinetics of oral contraceptives in healthy female volunteers. Journal of Clinical Pharmacology 41 683-690.

Keller H, Givel F, Perroud M \& Wahli W 1995 Signaling cross-talk between peroxisome proliferator-activated receptor/retinoid X receptor and estrogen receptor through estrogen response elements. Molecular Endocrinology 9 794-804.

Klotz DM, Hewitt SC, Ciana P, Raviscioni M, Lindzey JK, Foley J, Maggi A, DiAugustine RP \& Korach KS 2002 Requirement of estrogen receptor-alpha in insulin-like growth factor-1 (IGF-1)-induced uterine responses and in vivo evidence for IGF-1/estrogen receptor cross-talk. Journal of Biological 277 8531-8537.

Kressler D, Schreiber SN, Knutti D \& Kralli A 2002 The PGC-1-related protein PERC is a selective coactivator of estrogen receptor alpha. Journal of Biological Chemistry 277 13918-13925.

Lefebvre AM, Chen I, Desreumaux P, Najib J, Fruchart JC, Geboes K, Briggs M, Heyman R \& Auwerx J 1998 Activation of the peroxisome proliferator-activated receptor gamma promotes the development of colon tumors in C57BL/6J-APCMin/+ mice. Nature Medicine 4 1053-1057.

Liu RC, Hurtt ME, Cook JC \& Biegel LB 1996 Effect of the peroxisome proliferator, ammonium perfluorooctanoate (C8), on hepatic aromatase activity in adult male Crl:CD BR (CD) rats. Fundamental and Applied Toxicology 30 220-228.

Martin L, Finn CA \& Trinder G 1973 Hypertrophy and hyperplasia in the mouse uterus after oestrogen treatment: an autoradiographic study. Journal of Endocrinology 56 133-144.

Michalik L, Desvergne B \& Wahli W 2004 Peroxisome-proliferatoractivated receptors and cancers: complex stories. Nature Reviews Cancer 4 61-70.

Miller JR 2002 The Wnts. Genome Biology 3 1-15.

Miyamoto S, Baba H, Kuroda S, Kaibuchi K, Fukuda T, Maehara Y \& Saito T 2000 Changes in E-cadherin associated with cytoplasmic molecules in well and poorly differentiated endometrial cancer. British Journal of Cancer 83 1168-1175.

Nei H, Saito T, Yamasaki H, Mizumoto H, Ito E \& Kudo R 1999 Nuclear localization of beta-catenin in normal and carcinogenic endometrium. Molecular Carcinogenesis 25 207-218.

Nephew KP, Long X, Osborne E, Burke KA, Ahluwalia A \& Bigsby RM 2000 Effect of estradiol on estrogen receptor expression in rat uterine cell types. Biology of $\mathbf{6 2}$ 168-177.
Pritts EA, Zhao D, Ricke E, Waite L \& Taylor RN 2002

PPAR-gamma decreases endometrial stromal cell transcription and translation of RANTES in vitro. Journal of Clinical Endocrinology and Metabolism 87 1841-1844.

Qin C, Burghardt R, Smith R, Wormke M, Stewart J \& Safe S 2003 Peroxisome proliferator-activated receptor gamma agonists induce proteasome-dependent degradation of cyclin D1 and estrogen receptor alpha in MCF-7 breast cancer cells. Cancer Research 63 958-964.

Scully RE, Bonfiglio TA, Kurman RJ, Silverberg SG \& Wilkinson EJ 1994 Histological typing of female genital tract tumours. In International Histological Classification of Tumours, edn 2, pp 13-18. Geneva: WHO..

Shearer BG \& Hoekstra WJ 2003 Recent advances in peroxisome proliferator-activated receptor science. Current Medicinal Chemistry $10267-280$

Simmen RC, Zhang XL, Michel FJ, Min SH, Zhao G \& Simmen FA 2002 Molecular markers of endometrial epithelial cell mitogenesis mediated by the Sp/Kruppel-like factor BTEB1. DNA and Cell Biology 21 115-128.

Sivridis E, Giatromanolaki A, Koukourakis M \& Anastasiadis P 2001 Endometrial carcinoma: association of steroid hormone receptor expression with low angiogenesis and bcl-2 expression. Virchows Archiv 438 470-477.

Wang X \& Kilgore MW 2002 Signal cross-talk between estrogen receptor alpha and beta and the peroxisome proliferator-activated receptor gamma1 in MDA-MB-231 and MCF-7 breast cancer cells. Molecular and Cellular Endocrinology 194 123-133.

Wanichkul T, Han S, Huang RP \& Sidell N 2003 Cytokine regulation by peroxisome proliferator-activated receptor gamma in human endometrial cells. Fertility and Sterility $\mathbf{7 9}$ (Suppl 1) 763-769.

Xu S, Zhu BT, Cai MX \& Conney AH 2001a Stimulatory effect of clofibrate on the action of estradiol in the mammary gland but not in the uterus of rats. Journal of Pharmacology and Experimental Therapy $29750-56$.

Xu S, Zhu BT \& Conney AH $2001 b$ Stimulatory effect of clofibrate and gemfibrozil administration on the formation of fatty acid esters of estradiol by rat liver microsomes. Journal of Pharmacology and Experimental Therapy 296 188-197.

Received 3 May 2004

Accepted 24 May 2004

Made available online as an

Accepted Preprint 1 June 2004 